\title{
Experimental Study on Splitting Performance of Fiber Reinforced Asphalt Concrete
}

\author{
Chunshui Huang ${ }^{1,2 *}$, Faqi Chen ${ }^{3}$, Danying $\mathrm{Gao}^{4}$ \\ ${ }^{1}$ College of Civil Engineering, Xuchang University, Xuchang 461000, China \\ ${ }^{2}$ School of Civil Engineering, Zhengzhou University, Zhengzhou 450000, China \\ ${ }^{3}$ Henan Dezheng Highway Co., Ltd., Kaifeng 475000, China \\ ${ }^{4}$ Henan University of Engineering, Zhengzhou 450000, China
}

Corresponding Author Email: chunshuihuang@163.com

https://doi.org/10.18280/rcma.290108

Received: 10 November 2018

Accepted: 19 January 2019

\section{Keywords:}

road engineering, performance of splitting test, test research, fiber reinforced asphalt mixture

\begin{abstract}
The effects of temperature, fiber length and fiber mixing amount on the splitting performance of asphalt concrete were studied by the splitting test of different fiber mixing amount and length of fiber asphalt concrete at different temperatures. The effect mechanism of fiber on the splitting performance of asphalt concrete was analyzed. The relationship model between the split test parameters of fiber asphalt concrete and temperature, fiber length and fiber mixing amount were established. The results show that under the test conditions, the optimum length of polyester fiber is about $6 \mathrm{~mm}$, and the optimum dosage is about $0.2 \%$.
\end{abstract}

\section{INTRODUCTION}

The strength of asphalt concrete is not strong enough to resist the deformation caused by the temperature stress due to sudden temperature drop or tensile stress and shear stress generated by driving load [1], which is the cause of the cracking of asphalt concrete pavement and the failure of water stability, and is also one of the main forms of early road damage. To solve the early damage of asphalt concrete pavement such as cracking, pit slot and rutting, more and more attention has been paid to fiber asphalt concrete.

The study shows that [2-5] the splitting tensile strength of asphalt concrete is closely related to the crack resistance of pavement. In order to solve the early cracking and damage of asphalt concrete pavement, some studies have been done on the relationship between splitting tensile strength and temperature, and the effect factors of splitting tensile strength. According to the existing research results, the common asphalt concrete or modified asphalt concrete is taken as the research object, and the reference temperature is $15^{\circ} \mathrm{C}$. The splitting performance of fiber asphalt concrete, the cracking resistance mechanism of fiber, the relationship between splitting test parameters and temperature, the effect of fiber type, fiber aspect ratio and fiber mixing amount on the splitting test parameters still need to be further studied. In this study, AC$13 \mathrm{~F}$ asphalt mixture is used as matrix, fiber length and mixing amount are taken as parameters. Under the condition of optimum asphalt amount determined by Marshall Test, the splitting test of fiber asphalt concrete is carried out at different temperatures. The effects of temperature, fiber aspect ratio and fiber mixing amount on the splitting performance of asphalt concrete are systematically studied.

\section{MATERIAL AND TEST}

The test uses No. 70 road petroleum asphalt, polyester fibe
$\mathrm{r}(\mathrm{PF})$ with length of $3 \mathrm{~mm}, 6 \mathrm{~mm}, 9 \mathrm{~mm}$ and $12 \mathrm{~mm}$, and bas alt fiber (BF) with length of $6 \mathrm{~mm}$. The fiber mixing amount $\mathrm{P}_{\mathrm{f}}$ (the mass ratio of fiber to mineral material) is $0.1 \%, 0.2 \%$, $0.3 \%$ and $0.4 \%$, respectively. Coarse aggregate is basalt and fine aggregate is syenite. After sieving, washing and drying, $t$ he aggregate shall be remixed with limestone ore powder to $f$ orm AC-13F type gradation median value. Twelve grading se ries are formed with fiber length and fiber mixing amount as parameters, and the optimum asphalt amount OAC [6] is dete rmined by standard Marshall Test, as shown in Table 1 . The mixing method of the fiber asphalt mixture is that the aggrega te is added first, the fiber is stirred for 2 minutes, the fiber is $d$ ispersed in the aggregate in a fluffy state, then the asphalt is a dded and stirred for 2 minutes, the mineral powder is added a nd stirred for 1 minute.

Table 1. Optimum asphalt amount

\begin{tabular}{cccccc}
\hline $\begin{array}{c}\text { Mix } \\
\text { type }\end{array}$ & $\begin{array}{c}\text { Fibre } \\
\text { length } \\
/ \mathrm{mm}\end{array}$ & $\mathrm{P}_{\mathrm{f}} / \%$ & $\mathrm{OAC}_{1} / \%$ & $\mathrm{OAC}_{2} / \%$ & $\mathrm{OAC} / \%$ \\
\hline AC-13F & $/$ & $/$ & 5.48 & 5.17 & 5.32 \\
& 3 & 0.2 & 6.2 & 6.22 & 6.21 \\
& & 0.1 & 5.34 & 5.47 & 5.41 \\
PFAC- & 6 & 0.2 & 6.12 & 5.73 & 5.93 \\
13F & & 0.3 & 6.31 & 6.2 & 6.25 \\
& 9 & 0.4 & 6.33 & 6.4 & 6.37 \\
& 12 & 0.2 & 6.05 & 5.72 & 5.89 \\
& & 0.1 & 5.32 & 5.74 & 5.87 \\
BFAC- & 6 & 0.2 & 5.63 & 5.35 & 5.34 \\
13F & 6 & 0.3 & 5.91 & 5.63 & 5.79 \\
& & 0.4 & 6.32 & 6 & 6.16 \\
\hline
\end{tabular}

AC-13F asphalt mixture is used as the matrix to form the test piece under the optimum asphalt amount determined by Marshall test for the splitting test [7]. PF and BF with fiber mixing amount $\mathrm{P}_{\mathrm{f}}$ of $0.2 \%$ and length of $6 \mathrm{~mm}$ are used to 
form standard Marshall test piece under the optimum asphalt amount to study the effect of temperature on splint performance. The test temperature is $-30{ }^{\circ} \mathrm{C},-20{ }^{\circ} \mathrm{C},-10{ }^{\circ} \mathrm{C}, 0$ ${ }^{\circ} \mathrm{C}, 5^{\circ} \mathrm{C}, 10^{\circ} \mathrm{C}$ and $15^{\circ} \mathrm{C}$. In order to study the effect of fiber aspect ratio on splitting performance, $\mathrm{PF}$ with fiber mixing amount $\mathrm{P}_{\mathrm{f}}$ of $0.2 \%$ and with fiber length of $3 \mathrm{~mm}, 6 \mathrm{~mm}, 9$ $\mathrm{mm}$ and $12 \mathrm{~mm}$ is added. When studying the effect of fiber mixing amount on splitting performance, $\mathrm{PF}$ and $\mathrm{BF}$ with length of $6 \mathrm{~mm}$ are added. The fiber mixing amount is $0.1 \%$, $0.2 \%, 0.3 \%$ and $0.4 \%$ respectively and the test temperature is $-30{ }^{\circ} \mathrm{C},-20^{\circ} \mathrm{C} .-10{ }^{\circ} \mathrm{C}, 0{ }^{\circ} \mathrm{C}$ and $15^{\circ} \mathrm{C}$.

According to the splitting test result, the splitting tensile strength, tensile failure strain and stiffness modulus are calculated according to the following formulas respectively: $\mathrm{R}_{\mathrm{T}}=0.006287 \mathrm{P}_{\mathrm{T}} / \mathrm{h}$
$\varepsilon_{\mathrm{T}}=\mathrm{X}_{\mathrm{T}} \times(0.0307+0.0936 \mu) /(1.35+5 \mu)$

$\mathrm{S}_{\mathrm{T}}=\mathrm{P}_{\mathrm{T}} \times(0.27+1.0 \mu) /\left(\mathrm{h} \times \mathrm{X}_{\mathrm{T}}\right)$

$\mu=(0.1350 \mathrm{~A}-1.7940) /(-0.5 \mathrm{~A}-0.0314)$

$\mathrm{A}=\mathrm{Y}_{\mathrm{T}} / \mathrm{X}_{\mathrm{T}}$

where, $\mathrm{R}_{\mathrm{T}}$ is splitting tensile strength, $\mathrm{MPa} ; \mathrm{P}_{\mathrm{T}}$ is the maximum value of the test load, $\mathrm{N} ; \mu$ is Poisson's ratio. $\varepsilon_{\mathrm{T}}$ is the destructive tensile strain; $h$ is the height of the test piece, $\mathrm{mm}$; $\mathrm{Y}_{\mathrm{T}}$ is the total deformation of the test piece in the vertical direction; $\mathrm{X}_{\mathrm{T}}$ is the total deformation of test piece in horizontal direction, $\mathrm{mm} ; \mathrm{S}_{\mathrm{T}}$ is failure stiffness modulus, $\mathrm{MPa}$.

Table 2-Table 4 show the test results respectively.

Table 2. Splitting test results at different temperatures

\begin{tabular}{cccccccccc}
\hline Mix type & $\mathrm{T} /{ }^{\circ} \mathrm{C}$ & $\mathrm{P}_{\mathrm{T}} / \mathrm{KN}$ & $\mathrm{Y}_{\mathrm{T}} / \mathrm{mm}$ & $\mathrm{X}_{\mathrm{T}} / \mathrm{mm}$ & $\mathrm{A}$ & $\mu$ & $\mathrm{R}_{\mathrm{T}} / \mathrm{Mpa}$ & $\varepsilon \mathrm{T} / \mathrm{mm}$ & $\mathrm{S} / \mathrm{Mpa}$ \\
\hline & -30 & 40.53 & 0.69 & 0.101 & 6.832 & 0.25 & 4.013 & 0.004 & 3304 \\
& -20 & 37.5 & 0.79 & 0.115 & 6.870 & 0.25 & 3.713 & 0.004 & 2670 \\
AC-13F & -10 & 34.75 & 0.99 & 0.143 & 6.923 & 0.25 & 3.441 & 0.005 & 1975 \\
& 0 & 30.44 & 1.38 & 0.201 & 6.866 & 0.25 & 3.014 & 0.007 & 1241 \\
& 5 & 29.27 & 1.62 & 0.238 & 6.807 & 0.25 & 2.898 & 0.009 & 1016 \\
& 10 & 25.44 & 1.94 & 0.282 & 6.879 & 0.25 & 2.519 & 0.010 & 738 \\
PFAC-13F & 15 & 19.18 & 2.77 & 0.445 & 6.225 & 0.30 & 1.899 & 0.018 & 389 \\
& -30 & 39.88 & 0.44 & 0.064 & 6.875 & 0.25 & 3.948 & 0.002 & 5099 \\
& -20 & 34.38 & 0.54 & 0.078 & 6.923 & 0.25 & 3.404 & 0.003 & 3582 \\
& -10 & 31.28 & 0.62 & 0.091 & 6.813 & 0.25 & 3.097 & 0.003 & 2838 \\
& 5 & 28.25 & 0.69 & 0.101 & 6.832 & 0.25 & 2.797 & 0.004 & 2303 \\
& 10 & 24.06 & 0.78 & 0.114 & 6.842 & 0.25 & 2.778 & 0.004 & 2024 \\
& 15 & 21.87 & 1.46 & 0.232 & 6.293 & 0.30 & 2.165 & 0.009 & 842 \\
& -30 & 42.53 & 0.49 & 0.071 & 6.901 & 0.25 & 4.211 & 0.003 & 4883 \\
& -20 & 40.06 & 0.59 & 0.086 & 6.860 & 0.25 & 3.966 & 0.003 & 3820 \\
& -10 & 36.42 & 0.71 & 0.104 & 6.827 & 0.25 & 3.606 & 0.004 & 2886 \\
& 0 & 34.23 & 0.94 & 0.137 & 6.861 & 0.25 & 3.389 & 0.005 & 2049 \\
& 5 & 30.61 & 0.99 & 0.143 & 6.923 & 0.25 & 3.031 & 0.005 & 1740 \\
& 10 & 28.91 & 1.35 & 0.197 & 6.853 & 0.25 & 2.862 & 0.007 & 1205 \\
& 15 & 21.79 & 1.96 & 0.314 & 6.242 & 0.30 & 2.177 & 0.012 & 631 \\
\hline
\end{tabular}

\section{EFFECT OF TEMPERATURE ON SPLITTING PERFORMANCE}

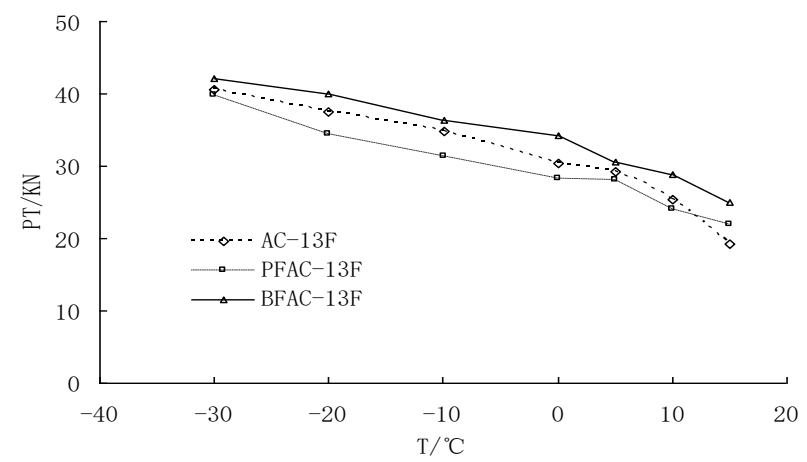

Figure 1. Relationship between splitting failure load and temperature

The relationship between spitting failure load and temperature based on Table 2 is shown in Figure 1. It can be seen that the splitting failure load of ordinary asphalt concrete and fiber asphalt concrete decreases with the increase of temperature because the splitting strength of asphalt concrete is mainly composed of the crushing force between aggregate, the internal grinding resistance, the shear strength of aggregate and the cohesion between asphalt and aggregate [2]. When the mixture ratio of asphalt mixture is determined, temperature becomes the main external factor to change the performance of asphalt so as to affect the strength of asphalt concrete.

First, the temperature determines the strength of the asphalt concrete by affecting the viscosity of the asphalt. When the temperature increases, the viscosity of the asphalt decreases and the cohesion between asphalt and aggregate decreases, so the overall strength of the asphalt concrete decreases. Meanwhile, as can be seen from Figure 2, part of the coarse aggregate on the fracture surface of the split test piece undergoes shear failure along the fracture surface under the action of splitting load, and another part of the coarse aggregate undergoes sliding failure along the fracture surface. The lower the temperature is, the larger the cohesion is. Thus, there will be fewer aggregates that will slip or deform on the fracture surface and more aggregates that will have shear cracking, and the splitting failure load of asphalt concrete will be larger. 


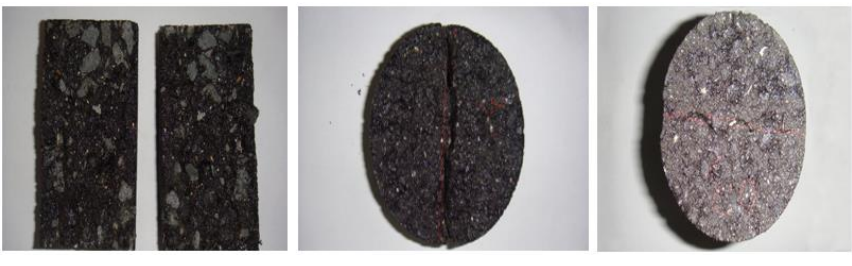

Figure 2. Failure forms of specimens

Second, temperature determines the splitting failure form of asphalt concrete by determining the mechanical property of asphalt. The mechanical property of asphalt is elasticity at low temperature, viscoelasticity in the equivalent temperature range, and viscosity at high temperature. At low temperature, asphalt concrete shows the elasticity that stress relaxation is not obvious [8]. Under the action of splitting load, the brittle failure of asphalt concrete occurs. Figure 3 is the spitting loaddeformation relationship curve. It can be seen that at $-30^{\circ} \mathrm{C}$, there is no obvious plastic falling section between the splitting failure load and the lateral displacement and the vertical displacement. The asphalt concrete shows obvious plasticity at high temperature. Under the action of splitting load, the asphalt concrete undergoes plastic failure. At $15{ }^{\circ} \mathrm{C}$, the asphalt is in the viscoelasticity stage. During the test, $80 \%$ of the maximum splitting failure load is taken as the control condition of whether to stop the test. The plastic falling section of the splitting failure load and the horizontal and vertical deformation process curve can be collected. When brittle failure occurs in a split test piece, the work done by the splitting load is mainly converted into dissipated energy and releasable energy stored in the test piece [9]. The more obvious the elasticity of asphalt mixture is, the smaller the plastic deformation of the split test piece is, the less dissipated energy is and the more stored released energy is, so the larger the splitting failure load is. During the plastic failure, the larger the plastic deformation of the test piece during the loading is, the more the dissipation energy is, the less the stored released energy is, so the smaller the splitting failure load is.
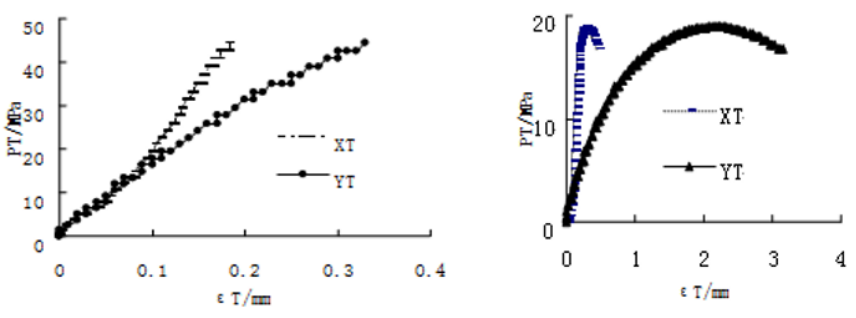

Figure 3. Typical splitting test process curve

It can be seen from the test results that the relationship between splitting failure load and temperature of ordinary asphalt concrete has a strong linear characteristic. When the temperature is lower than the fraass breaking point $\mathrm{T}_{\mathrm{f}}=0^{\circ} \mathrm{C}$, the asphalt exhibits strong brittleness and the asphalt concrete shows strong elasticity, showing that the slope of the relationship between $\mathrm{P}_{\mathrm{T}}$ and temperature $\mathrm{T}$ is small. When the temperature is higher than the fraass breaking point, the viscoelasticity of asphalt increases, and the Elastoplast city of asphalt concrete becomes obvious, which shows that the slope of the relationship between $\mathrm{P}_{\mathrm{T}}$ and temperature $\mathrm{T}$ increases. For ordinary asphalt concrete, the linear relationship between splitting failure load and temperature can be expressed by Formulas (1) and (2):
$\mathrm{P}_{\mathrm{T}}=-0.3302 \mathrm{~T}+30.852 \mathrm{R}^{2}=0.9895 \mathrm{~T}<\mathrm{T}_{\mathrm{f}}$

$\mathrm{P}_{\mathrm{T}}=-1.009 \mathrm{~T}+34.72 \quad \mathrm{R}^{2}=0.9810 \mathrm{~T}>\mathrm{T}_{\mathrm{f}}$

In the temperature range of $-30{ }^{\circ} \mathrm{C}-15{ }^{\circ} \mathrm{C}$, the relationship between splitting failure load and temperature of fiber asphalt concrete varies linearly obviously. For PF asphalt concrete, the relationship between splitting failure load and temperature is as follows:

$\mathrm{P}_{\mathrm{T}}=-0.36824 \mathrm{~T}+28.1075 \mathrm{R}^{2}=0.9741$

For BF asphalt concrete, the relationship between splitting failure load and temperature is as follows:

$\mathrm{P}_{\mathrm{T}}=-0.449304 \mathrm{~T}+30.8673 \quad \mathrm{R}^{2}=0.9385$

The effect of temperature on splitting tensile strength $\mathrm{R}_{\mathrm{T}}$ and $\mathrm{P}_{\mathrm{T}}$ is similar, and both of them decrease with the increase of temperature. From the test results, it can be seen that the splitting tensile strength of BF asphalt concrete at low or high temperature is much higher than that of ordinary asphalt concrete because the fibers with uniform dispersion and crisscross three-dimensional network structure inhibits the slip between aggregates under external force. The overall strength of the asphalt concrete is improved, and the fiber has a better reinforcing effect on the asphalt concrete. Especially, when the asphalt is in the high-temperature viscoelasticity stage, the reinforcing effect is more obvious. When the temperature of $\mathrm{PF}$ asphalt concrete is more than $10^{\circ} \mathrm{C}$, the splitting tensile strength changes from lower than that of ordinary asphalt concrete to greater than that of ordinary asphalt concrete.

The low-temperature splitting tensile strength of PF asphalt concrete is lower than that of ordinary asphalt concrete because the optimum asphalt amount OAC obtained by Marshall test is large, and the free asphalt acts as a lubricant for the slip of aggregate in asphalt concrete. When this effect is greater than the reinforcing effect of the fiber, the reinforcing function of the fiber is covered up. When the temperature increases, the contribution rate of the asphalt to the strength decreases, and the reinforcing function of the fiber is reflected. In practical engineering application, it is feasible to determine the optimum asphalt amount of fiber asphalt concrete by Marshall test, and it is also necessary to seek more accurate test method to determine the amount of asphalt to be added into the asphalt concrete after fiber is added.

The failure tensile strain is linearly related to the horizontal deformation. With the increase of temperature, the cohesion of asphalt decreases and the horizontal deformation increases, so the failure tensile strain increases. After the fiber is added, the three-dimensional network structure of the fiber effectively prevents the development of the deformation, and the failure tensile strain of the fiber asphalt concrete is reduced.

With the increase of temperature, $\mathrm{P}_{\mathrm{T}}$ decreases and the failure stiffness modulus of asphalt concrete decreases. When the fiber is added, the splitting failure load increases, the horizontal deformation decreases, and the failure stiffness modulus of asphalt concrete increases. The linear relationship between the failure stiffness modulus $\mathrm{S}_{\mathrm{T}}$ and the temperature of asphalt concrete is obvious. For ordinary asphalt concrete, the relationship between failure stiffness modulus ST and temperature $\mathrm{T}$ is as follows:

$\mathrm{S}_{\mathrm{T}}=-65.0142 \mathrm{~T}+1340.4629 \mathrm{R}^{2}=0.9980$ 
The linear relationship between the failure stiffness modulus $\mathrm{S}_{\mathrm{T}}$ of $\mathrm{PF}$ asphalt concrete and temperature is as follows:

$\mathrm{S}_{\mathrm{T}}=-88.911 \mathrm{~T}+2148.524 \mathrm{R}^{2}=0.9680$

The linear relationship between the failure stiffness modulus $\mathrm{S}_{\mathrm{T}}$ of $\mathrm{BF}$ asphalt concrete and temperature is as follows:

$\mathrm{S}_{\mathrm{T}}=-91.0983 \mathrm{~T}+2068.485 \quad \mathrm{R}^{2}=0.9968$

Table 3. Splitting test results for different fiber length

\begin{tabular}{|c|c|c|c|c|c|c|c|c|c|c|}
\hline Mix type & Fibre length / mm & $\mathrm{T} /{ }^{\circ} \mathrm{C}$ & $\mathrm{P}_{\mathrm{T}} / \mathrm{KN}$ & $\mathrm{Y}_{\mathrm{T}} / \mathrm{mm}$ & $\mathrm{X}_{\mathrm{T}} / \mathrm{mm}$ & A & $\mu$ & $\mathrm{R}_{\mathrm{T}} / \mathrm{MPa}$ & $\varepsilon_{\mathrm{T}} / \mathrm{mm}$ & $\mathrm{S}_{\mathrm{T}} / \mathrm{MPa}$ \\
\hline \multirow{20}{*}{ PFAC-13F } & \multirow{5}{*}{3} & -30 & 40.40 & 0.58 & 0.084 & 6.905 & 0.25 & 4.000 & 0.003 & 3919 \\
\hline & & -20 & 36.92 & 0.69 & 0.101 & 6.832 & 0.25 & 3.655 & 0.004 & 3010 \\
\hline & & -10 & 34.75 & 0.82 & 0.119 & 6.891 & 0.25 & 3.441 & 0.004 & 2384 \\
\hline & & 0 & 32.27 & 1.63 & 0.237 & 6.878 & 0.25 & 3.195 & 0.009 & 1114 \\
\hline & & 15 & 14.10 & 2.31 & 0.368 & 6.277 & 0.30 & 1.396 & 0.014 & 343 \\
\hline & \multirow{5}{*}{6} & -30 & 39.88 & 0.44 & 0.064 & 6.875 & 0.25 & 3.948 & 0.002 & 5099 \\
\hline & & -20 & 34.38 & 0.54 & 0.078 & 6.923 & 0.25 & 3.404 & 0.003 & 3582 \\
\hline & & -10 & 31.28 & 0.62 & 0.091 & 6.813 & 0.25 & 3.097 & 0.003 & 2838 \\
\hline & & 0 & 28.25 & 0.69 & 0.101 & 6.832 & 0.25 & 2.797 & 0.004 & 2303 \\
\hline & & 15 & 21.87 & 1.46 & 0.232 & 6.293 & 0.30 & 2.165 & 0.009 & 842 \\
\hline & \multirow{5}{*}{9} & -30 & 40.27 & 0.38 & 0.055 & 6.909 & 0.25 & 3.987 & 0.002 & 5962 \\
\hline & & -20 & 35.73 & 0.86 & 0.124 & 6.935 & 0.25 & 3.538 & 0.005 & 2337 \\
\hline & & -10 & 34.11 & 0.92 & 0.133 & 6.917 & 0.25 & 3.377 & 0.005 & 2086 \\
\hline & & 0 & 30.46 & 1.31 & 0.189 & 6.931 & 0.25 & 3.016 & 0.007 & 1308 \\
\hline & & 15 & 17.38 & 2.29 & 0.364 & 6.291 & 0.30 & 1.721 & 0.014 & 427 \\
\hline & \multirow{5}{*}{12} & -30 & 39.89 & 0.28 & 0.041 & 6.829 & 0.25 & 3.949 & 0.002 & 8014 \\
\hline & & -20 & 39.43 & 0.36 & 0.052 & 6.923 & 0.25 & 3.904 & 0.002 & 6162 \\
\hline & & -10 & 38.46 & 0.51 & 0.074 & 6.892 & 0.25 & 3.808 & 0.003 & 4243 \\
\hline & & 0 & 34.14 & 0.76 & 0.111 & 6.847 & 0.25 & 3.380 & 0.004 & 2527 \\
\hline & & 15 & 13.78 & 2.34 & 0.374 & 6.257 & 0.30 & 1.364 & 0.015 & 331 \\
\hline
\end{tabular}

Figure 4 shows three typical distribution forms of fiber on the fracture surface of a split test piece. For the fiber distributed in a state, the length is seriously uneven along the fracture surface. When the temperature is low and the asphalt is brittle, brittle fracture occurs in the split test piece. The tensile stress provided at the interface formed by the asphalt, fiber, aggregate and filler is sufficient to cause the fiber to be stretched along the fracture surface until it breaks. When the temperature increases, the asphalt turns from brittleness to viscoelasticity and the tensile stress at the interface decreases gradually. The fiber length distributed on the fracture surface is too short, the fiber slips one-way due to insufficient tensile stress until it is detached from the interface and no longer subjected to tensile stress. For the fiber distributed in b state, the length is not uniform along the fracture surface. When the test piece has brittle failure at low temperature, the interfacial tensile stress causes the fiber to fracture. When the temperature increases, the asphalt turns from brittleness to viscoelasticity. Due to insufficient cohesion in the interface, one-way slip of the fiber occurs at the interface, and sufficient length is distributed along both ends of the fracture surface so that the fiber is always pulled during the sliding process of the interface without breaking until the test piece is broken. At this time, the tensile stress of the fiber contributes to the fracture strength and tensile strength of the test piece. For the fiber distributed in c state, the length is uniformly distributed on both sides of the fracture surface. The interfacial tensile stress is large at low temperature, and the fiber breaks. When the temperature increases, the cohesion decreases at the interface and fiber slides bidirectionally along the fracture surface. Under the appropriate fiber aspect ratio condition, the fiber is always under tension without breaking until the test piece is broken, and the fiber is subjected to greater tensile stress than the fiber with the b-type distribution. At this time, the contribution rate of fiber to splitting strength and tensile strength of asphalt concrete is larger than that of b-type fiber. If the aspect ratio of the fiber is too large, the fiber fractures due to excessive tensile stress, thereby pushing the fiber into tensile stress.

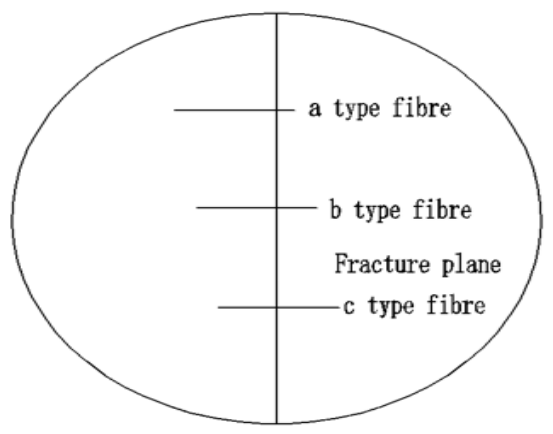

Figure 4. Schematic diagram of fiber distribution on fracture surface

It can be seen from the test results that when the fiber length is $3 \mathrm{~mm}$ and the temperature is $-30{ }^{\circ} \mathrm{C}$, the splitting failure load and the maximum tensile strength of PF asphalt concrete appear. This is because the shorter the fiber is, the smaller the aspect ratio is, the greater the number of fiber is, and the larger number of tensile stress-bearing fiber distributed on the splitting failure fracture surface is. At low temperature, brittle failure occurs in the test piece and the fiber is firmly adhered to the asphalt. At the interface formed by the asphalt, fiber, aggregate and filler, the fiber with the typical distribution of a, 
$\mathrm{b}$ and $\mathrm{c}$ are broken under the tensile stress of the interface. The tensile stress of the fiber contributes to the tensile strength of the asphalt concrete, so the failure load and the tensile strength of the asphalt concrete have the maximum value under this condition.

When the fiber length is $12 \mathrm{~mm}$ and the temperature is $0{ }^{\circ} \mathrm{C}$ $20^{\circ} \mathrm{C}$, the splitting failure load and splitting tensile strength of the fiber asphalt concrete are larger than those of the fiber asphalt concrete with the aspect ratio of other fibers, and the tensile strain is small. This is because the asphalt concrete in this temperature range is in a transition from elasticity to viscoelasticity, and the fiber aspect ratio increases. The number of fibers distributed on the fracture surface decreases, but the fiber length increases. The number of fibers distributed uniformly along the fracture surface increases, and the tensile stress at the interface is increased. In the process of gradually increasing the temperature, fewer and fewer fibers are broken, and the tensile stress of the fibers without fracture is increased, so the strength of asphalt concrete decreases with the change of temperature, and the value is relatively large. At this time, fiber asphalt concrete shows good mechanical property.

When the temperature is $15^{\circ} \mathrm{C}$, the splitting failure load and tensile strength of fiber asphalt concrete with fiber length of 6 $\mathrm{mm}$ have peak values. This is because at this temperature, the splitting failure of asphalt concrete has an obvious plastic stage. For the fibers on the fracture surface, a-type fibers mainly slip in one direction until they exit from the tensile stress and btype fibers exhibit bidirectional slip. As the crack grows, the tensile stress experienced by the crack becomes smaller and smaller. c-type fibers mainly exhibit bidirectional slip if the ctype fibers are too short and will break due to the high cohesion of the interface if fibers are too long. When the fiber is $6 \mathrm{~mm}$ long, fibers in c-type distribution are not broken due to excessive tensile stress, and the number of fibers is smaller than that of fibers that are $3 \mathrm{~mm}$ long, but the number of fibers with a-type slip is also reduced. The tensile stress experienced by a single fiber is increased. Although a $6 \mathrm{~mm}$ fiber is less stressed than a $9 \mathrm{~mm}$ and $12 \mathrm{~mm}$ single fiber, the asphalt concrete with a fiber length of $6 \mathrm{~mm}$ has good tensile failure mechanical property because the number of fibers breaking due to the increase of tensile stress because of the increase of the fiber aspect ratio is reduced.

To sum up, the effect of fiber on the splitting performance of asphalt concrete is mainly related to the distribution form, number of fibers on the fracture surface and the fiber aspect ratio. In the process where asphalt concrete is subjected to the alternating effect of high and low temperature, for the fiber of about $6 \mathrm{~mm}$ compared with fiber of $3 \mathrm{~mm}$ in the same amount condition, the tensile stress of the fiber is increased caused by the increase of length. Thus, the loss of the reduction in tensile strength caused by the reduction in the number of fibers distributed at the fracture surface is compensated. As compared with the fibers of $9 \mathrm{~mm}$ and $12 \mathrm{~mm}$ in length, the number of fibers broken due to too long fibers and too large interfacial adhesion is reduced, thereby compensating for the loss of the reduction in tensile stress of a single fiber. Hence, $6 \mathrm{~mm}$ corresponds to the optimum length of the fiber.

\section{EFFECT OF FIBER AMOUNT ON SPLITTING PERFORMANCE}

From the test results, it can be seen that for BF asphalt concrete, the temperature changes from $-30{ }^{\circ} \mathrm{C}$ to $15^{\circ} \mathrm{C}$, the mixing amount changes from $0.1 \%$ to $0.4 \%$ and the splitting failure load is larger than that of ordinary asphalt concrete under the same temperature. After the fibers are dispersed, they are uniformly distributed in the asphalt mixture to form a spatial three-dimensional fiber grid, so that the horizontal and vertical deformation of the asphalt concrete under the splitting load is retarded. Thus, fibers can enhance the strength of asphalt concrete. When the temperature is lower than $15^{\circ} \mathrm{C}$, the effect of fiber mixing amount on splitting failure load is not obvious. This is because the strength of fiber asphalt concrete is related to the amount of asphalt, the amount of fiber, the distribution form and number of fiber on the fracture surface. The performance of asphalt is affected by temperature, which is from brittleness at low temperature to viscoelasticity at high temperature, and the splitting failure of asphalt concrete is also characterized by brittle fracture at low temperature and elastic-plastic failure at high temperature. When the test piece is fractured and brittle at low temperature, the fibers distributed on the fracture surface are broken. After the temperature rises, the asphalt concrete will undergo elasticplastic failure, and some of the fibers distributed laterally along the fracture surface will slip and the other part will be broken. Therefore, at low temperature, under the comprehensive effect of asphalt property, fiber distribution form and fiber quantity, the fiber mixing amount is not the main factor, so the effect law of fiber mixing amount is not obvious. At $15{ }^{\circ} \mathrm{C}$, the splitting failure load of fiber asphalt concrete increases with the increase of fiber mixing amount. In the condition of this temperature, the asphalt is in the viscoelasticity stage, the splitting failure of the asphalt concrete has obvious plastic stage, the interfacial cohesion of the aggregate, asphalt and filler is small, the tensile stress on the interface of the single fiber is reduced, and the number of fibers under tension fracture becomes smaller. Besides, the number of fibers sliding along the interface under tensile stress increases, the effect of fiber number on the strength of asphalt concrete is dominant compared with other effect factors. Under the condition of appropriate fiber mixing amount, the larger the fiber mixing amount is, the greater the number of fibers distributed on the fracture surface is and the greater the tensile stress is.

For PF asphalt concrete, the effect of fiber on splitting failure load and tensile strength of asphalt concrete is consistent with that of BF. When the temperature is lower than $10{ }^{\circ} \mathrm{C}$, the splitting failure load and tensile strength of partially mixed fiber asphalt concrete are less than those of BF asphalt concrete and ordinary asphalt concrete. This is because the optimum asphalt amount of asphalt concrete mixed with PF through Marshall test is larger than that of ordinary asphalt concrete and $\mathrm{BF}$ asphalt concrete. The lower the temperature is, the more obvious the brittleness of asphalt is, the more obvious the crack failure of the asphalt concrete is and the more obvious the elasticity is. At this time, the asphalt content in the asphalt concrete is larger, the free asphalt content is higher, the embedment effect between aggregate is smaller, and the strength is lower. The effect of asphalt amount on the splitting strength of asphalt concrete covers up the reinforcing effect of fiber to some extent. At $15^{\circ} \mathrm{C}$, the splitting failure load of PF asphalt concrete is higher than that of ordinary asphalt concrete. This is because, at this temperature, the cohesion of the asphalt at the viscoelasticity stage decreases, the effect of the tensile reinforcement of the fiber relative to the increase of the amount of asphalt on the strength of the asphalt concrete is dominant so that the reinforcing effect of 
the fiber is revealed. When the temperature is $15^{\circ} \mathrm{C}$, the splitting failure load value of $\mathrm{PF}$ asphalt concrete with equal mixing amount is higher than that of $\mathrm{BF}$ asphalt concrete. PF is a synthetic fiber through polyester formed by polycondensation of organic dibasic acid and dihydric alcohol, and by spinning. The $\mathrm{BF}$ is a continuous fiber formed by melting basalt stone material at $1,450-1,500{ }^{\circ} \mathrm{C}$ and drawing at a high speed through a platinum-rhodium alloy drawing drain plate. It is a PF containing an organic component and an organic substance in a pitch component with better bonding capacity. In the process of loading the split test piece, the fiber which is not broken slides along the interface composed of asphalt, aggregate and filler on the fracture surface. The stronger the bonding capacity of the fiber and the asphalt is, the greater the tensile stress applied to the fiber is, the higher the overall strength of the test piece is and the greater the splitting failure load is.

Table 4. Splitting test results of different fiber amount

\begin{tabular}{|c|c|c|c|c|c|c|c|c|c|c|}
\hline Mix type & $\mathrm{P}_{\mathrm{f}} / \%$ & $\mathrm{~T} /{ }^{\circ} \mathrm{C}$ & $\mathrm{P}_{\mathrm{T}} / \mathrm{KN}$ & $\mathrm{Y}_{\mathrm{T}} / \mathrm{mm}$ & $\mathrm{X}_{\mathrm{T}} / \mathrm{mm}$ & A & $\mu$ & $\mathrm{R}_{\mathrm{T}} / \mathrm{MPa}$ & $\varepsilon_{\mathrm{T}} / \mathrm{mm}$ & $\mathrm{S}_{\mathrm{T}} / \mathrm{MPa}$ \\
\hline \multirow{6}{*}{$\mathrm{AC}-13 \mathrm{~F}$} & \multirow{5}{*}{ I } & -30 & 40.53 & 0.69 & 0.101 & 6.832 & 0.25 & 4.013 & 0.004 & 3304 \\
\hline & & -20 & 37.50 & 0.79 & 0.115 & 6.870 & 0.25 & 3.713 & 0.004 & 2670 \\
\hline & & -10 & 34.75 & 0.99 & 0.143 & 6.923 & 0.25 & 3.441 & 0.005 & 1975 \\
\hline & & 0 & 30.44 & 1.38 & 0.201 & 6.866 & 0.25 & 3.014 & 0.007 & 1241 \\
\hline & & 15 & 19.18 & 2.77 & 0.445 & 6.225 & 0.30 & 1.899 & 0.018 & 389 \\
\hline & \multirow{5}{*}{0.1} & -30 & 39.38 & 0.56 & 0.082 & 6.829 & 0.25 & 3.899 & 0.003 & 3956 \\
\hline \multirow{17}{*}{ PFAC-13F } & & -20 & 36.36 & 0.71 & 0.104 & 6.827 & 0.25 & 3.600 & 0.004 & 2881 \\
\hline & & -10 & 34.52 & 0.84 & 0.122 & 6.885 & 0.25 & 3.418 & 0.004 & 2312 \\
\hline & & 0 & 31.94 & 1.09 & 0.159 & 6.855 & 0.25 & 3.162 & 0.006 & 1648 \\
\hline & & 15 & 19.68 & 2.17 & 0.344 & 6.308 & 0.30 & 1.948 & 0.013 & 510 \\
\hline & \multirow{5}{*}{0.2} & -30 & 39.88 & 0.44 & 0.064 & 6.875 & 0.25 & 3.948 & 0.002 & 5099 \\
\hline & & -20 & 34.38 & 0.54 & 0.078 & 6.923 & 0.25 & 3.404 & 0.003 & 3582 \\
\hline & & -10 & 31.28 & 0.62 & 0.091 & 6.813 & 0.25 & 3.097 & 0.003 & 2838 \\
\hline & & 0 & 28.25 & 0.69 & 0.101 & 6.832 & 0.25 & 2.797 & 0.004 & 2303 \\
\hline & & 15 & 21.87 & 1.46 & 0.232 & 6.293 & 0.30 & 2.165 & 0.009 & 842 \\
\hline & \multirow{5}{*}{0.3} & -30 & 37.89 & 0.38 & 0.055 & 6.909 & 0.25 & 3.751 & 0.002 & 5610 \\
\hline & & -20 & 37.51 & 0.59 & 0.086 & 6.860 & 0.25 & 3.714 & 0.003 & 3577 \\
\hline & & -10 & 35.36 & 0.89 & 0.129 & 6.899 & 0.25 & 3.501 & 0.005 & 2235 \\
\hline & & 0 & 31.96 & 1.69 & 0.246 & 6.870 & 0.25 & 3.164 & 0.009 & 1064 \\
\hline & & 15 & 25.84 & 1.84 & 0.293 & 6.280 & 0.30 & 2.558 & 0.011 & 789 \\
\hline & \multirow{5}{*}{0.4} & -30 & 39.81 & 0.33 & 0.048 & 6.875 & 0.25 & 3.942 & 0.002 & 6787 \\
\hline & & -20 & 41.53 & 0.56 & 0.082 & 6.829 & 0.25 & 4.112 & 0.003 & 4172 \\
\hline & & -10 & 36.04 & 0.85 & 0.123 & 6.911 & 0.25 & 3.568 & 0.004 & 2385 \\
\hline \multirow{22}{*}{ BFAC-13F } & & 0 & 30.97 & 1.73 & 0.254 & 6.811 & 0.25 & 3.066 & 0.009 & 1007 \\
\hline & & 15 & 26.97 & 2.16 & 0.342 & 6.316 & 0.30 & 2.670 & 0.013 & 702 \\
\hline & \multirow{5}{*}{0.1} & -30 & 41.06 & 0.56 & 0.081 & 6.914 & 0.25 & 4.065 & 0.003 & 4125 \\
\hline & & -20 & 39.80 & 0.69 & 0.100 & 6.900 & 0.25 & 3.941 & 0.004 & 3245 \\
\hline & & -10 & 38.27 & 0.93 & 0.135 & 6.889 & 0.25 & 3.789 & 0.005 & 2315 \\
\hline & & 0 & 35.25 & 1.43 & 0.207 & 6.908 & 0.25 & 3.490 & 0.008 & 1387 \\
\hline & & 15 & 19.59 & 2.06 & 0.331 & 6.224 & 0.30 & 1.940 & 0.013 & 534 \\
\hline & \multirow{6}{*}{0.2} & -30 & 42.53 & 0.49 & 0.071 & 6.901 & 0.25 & 4.211 & 0.003 & 4883 \\
\hline & & -20 & 40.06 & 0.59 & 0.086 & 6.860 & 0.25 & 3.966 & 0.003 & 3820 \\
\hline & & -10 & 36.42 & 0.71 & 0.104 & 6.827 & 0.25 & 3.606 & 0.004 & 2886 \\
\hline & & 0 & 34.23 & 0.94 & 0.137 & 6.861 & 0.25 & 3.389 & 0.005 & 2049 \\
\hline & & 15 & 21.79 & 1.96 & 0.314 & 6.242 & 0.30 & 2.177 & 0.012 & 631 \\
\hline & & -30 & 43.60 & 0.46 & 0.067 & 6.866 & 0.25 & 4.317 & 0.002 & 5332 \\
\hline & \multirow{4}{*}{0.3} & -20 & 42.04 & 0.59 & 0.086 & 6.860 & 0.25 & 4.162 & 0.003 & 4008 \\
\hline & & -10 & 40.40 & 0.78 & 0.113 & 6.903 & 0.25 & 4.000 & 0.004 & 2914 \\
\hline & & 0 & 35.01 & 1.28 & 0.188 & 6.809 & 0.25 & 3.466 & 0.007 & 1539 \\
\hline & & 15 & 25.57 & 1.61 & 0.258 & 6.240 & 0.30 & 2.532 & 0.010 & 893 \\
\hline & \multirow{5}{*}{0.4} & -30 & 44.50 & 0.43 & 0.063 & 6.825 & 0.25 & 4.406 & 0.002 & 5822 \\
\hline & & -20 & 42.52 & 0.63 & 0.092 & 6.848 & 0.25 & 4.210 & 0.003 & 3797 \\
\hline & & -10 & 39.97 & 0.88 & 0.128 & 6.875 & 0.25 & 3.957 & 0.005 & 2555 \\
\hline & & 0 & 34.73 & 0.98 & 0.143 & 6.853 & 0.25 & 3.439 & 0.005 & 1994 \\
\hline & & 15 & 26.53 & 1.52 & 0.241 & 6.307 & 0.30 & 2.627 & 0.009 & 981 \\
\hline
\end{tabular}

When the temperature is $15{ }^{\circ} \mathrm{C}$ and $\mathrm{P}_{\mathrm{f}} \leq 0.4 \%$, the linear relationship between splitting failure load and fiber mixing amount of PF asphalt concrete is as follows:

$\mathrm{P}_{\mathrm{T}}=21.74 \mathrm{P}_{\mathrm{f}}+18.36 \quad \mathrm{R}^{2}=0.9398$

When the temperature is $15{ }^{\circ} \mathrm{C}$ and $\mathrm{P}_{\mathrm{f}} \leq 0.4 \%$, the linear relationship between splitting failure load and fiber mixing amount of BF asphalt concrete is as follows:
$\mathrm{P}_{\mathrm{T}}=20.68 \mathrm{P}_{\mathrm{f}}+18.396 \quad \mathrm{R}^{2}=0.9367$

It can be seen from the test results that the vertical deformation and horizontal deformation of asphalt concrete decrease with the increase of fiber mixing amount in splitting failure. This is because, with an appropriate amount of fiber, the larger the fiber mixing amount is, the larger the spatial fiber grid density uniformly dispersed in the asphalt mixture is, and the higher the overall strength of the asphalt concrete is. At the 
same time, the larger the fiber mixing amount is, the more fibers distributed on the fracture surface is, so the deformation of the fiber asphalt concrete will decrease with the increase of the fiber mixing amount under the splitting load.

It can be seen from the test results that when the temperature is lower than $15^{\circ} \mathrm{C}$, the tendency of splitting tensile strength with the increase of fiber mixing amount is not obvious. This is because the elasticity of asphalt concrete is obvious at low temperature, and the contribution of fiber tensile reinforcement to the overall strength of asphalt concrete relative to the cohesion of asphalt and the embedment between aggregates does not occupy the dominant position. At $15^{\circ} \mathrm{C}$, the splitting tensile strength increases obviously with the increase of fiber mixing amount. This is because, under this temperature condition, the Elastoplast city of asphalt concrete is obvious, the cohesion of asphalt decreases, and the overall strength of asphalt mixture decreases, so the reinforcing effect of the fiber begins to appear. Under the proper mixing amount of fiber, the larger the fiber mixing amount is, the more fibers subjected to tensile stress on the fracture surface is, and the higher the tensile strength is.

For $\mathrm{PF}$, when the temperature is $15^{\circ} \mathrm{C}$ and $\mathrm{Pf} \leq 0.4 \%$, the linear relationship between splitting tensile strength $\mathrm{R}_{\mathrm{T}}$ of asphalt concrete and fiber mixing amount $\mathrm{P}_{\mathrm{f}}$ is as follows:

$\mathrm{R}_{\mathrm{T}}=2.152 \mathrm{P}_{\mathrm{f}}+1.818 \mathrm{R}^{2}=0.9396$

For BF, when the temperature is $15^{\circ} \mathrm{C}$ and $\mathrm{P}_{\mathrm{f}} \leq 0.4 \%$, the linear relationship between splitting tensile strength RT of asphalt concrete and fiber mixing amount $\mathrm{P}_{\mathrm{f}}$ is as follows:

$\mathrm{R}_{\mathrm{T}}=2.048 \mathrm{P}_{\mathrm{f}}+1.822 \quad \mathrm{R}^{2}=0.9367$

It can be seen from the test results that at low temperature, the tensile strain $\varepsilon_{\mathrm{T}}$ of PF asphalt concrete decreases slightly with the increase of fiber mixing amount. This is because when splitting fracture occurs in asphalt concrete at low temperature, the fibers distributed laterally on the fracture surface mainly suffer from fracture failure, and the fibers have a retardation effect on the development of the lateral displacement. The larger the fiber mixing amount is, the larger the number of fibers distributed on the fracture surface subjected to tensile stress is and the smaller the tensile strain of asphalt concrete is. The tensile strain $\varepsilon_{\mathrm{T}}$ of $\mathrm{PF}$ asphalt concrete at $15{ }^{\circ} \mathrm{C}$ decreases and then increases with the increase of the fiber mixing amount. When the fiber mixing amount is $0.2 \%$, the tensile strain reaches the minimum, and the retardation effect of the fiber on the lateral displacement is most obvious. The effect of the fiber is optimally exerted, the fiber mixing amount corresponds to the optimum amount of fiber, and the excess fiber can't fully exert its effect.

When the temperature is $15{ }^{\circ} \mathrm{C}$ and $\mathrm{P}_{\mathrm{f}} \leq 0.4 \%$, the relationship between tensile strain $\varepsilon_{\mathrm{T}}$ and fiber mixing amount of $\mathrm{PF}$ asphalt concrete is as follows:

$\varepsilon_{\mathrm{T}}=0.015741-0.0228268 \mathrm{P}_{\mathrm{f}}+0.027067 \mathrm{P}_{\mathrm{f}}^{2}$

When the temperature is $15{ }^{\circ} \mathrm{C}$ and the fiber mix amount $\mathrm{P}_{\mathrm{f}}$ $\leq 0.4 \%$, the tensile strain $\varepsilon_{\mathrm{T}}$ of BF asphalt concrete decreases with the increase of the fiber mixing amount, and the fiber mixing amount hasn't reached the optimum. The fibers can be uniformly dispersed in the asphalt concrete, and the reinforcing effect of the fibers is fully exerted. In this case, the quadratic curve relation between the tensile strain $\varepsilon_{\mathrm{T}}$ of asphalt concrete and the fiber mixing amount is:

$\varepsilon_{\mathrm{T}}=0.016605-0.0210932 \mathrm{P}_{\mathrm{f}}+0.000233 \mathrm{P}_{\mathrm{f}}^{2}$

It can be seen from the test results that the failure stiffness modulus $\mathrm{S}_{\mathrm{T}}$ of $\mathrm{PF}$ asphalt concrete at $-30{ }^{\circ} \mathrm{C}$ increases with the increase of fiber mixing amount. With the increase of temperature, the failure stiffness modulus $\mathrm{S}_{\mathrm{T}}$ increases first and then decreases with the increase of fiber mixing amount. When the temperature is $15^{\circ} \mathrm{C}$ and $\mathrm{P}_{\mathrm{f}} \leq 0.4 \%$, the relationship between the failure stiffness modulus $\mathrm{S}_{\mathrm{T}}$ of $\mathrm{PF}$ asphalt concrete and the fiber mixing amount $\mathrm{P}_{\mathrm{f}}$ is as follows:

$\mathrm{S}_{\mathrm{T}}=350.971+3193.571 \mathrm{P}_{\mathrm{f}}-5721.43 \mathrm{P}_{\mathrm{f}}^{2}$

When the temperature is $15^{\circ} \mathrm{C}$ and $\mathrm{P}_{\mathrm{f}} \leq 0.4 \%$, the optimum content of BF hasn't reached yet, and the modulus of failure stiffness $\mathrm{S}_{\mathrm{T}}$ increases with the increase of fiber amount, and it is in the rising stage of quadratic curve. In this case, the quadratic relationship between the failure stiffness modulus $\mathrm{S}_{\mathrm{T}}$ of $\mathrm{BF}$ asphalt concrete and the fiber mixing amount $\mathrm{P}_{\mathrm{f}}$ is as follows:

$\mathrm{S}_{\mathrm{T}}=57.026-304.557 \mathrm{P}_{\mathrm{f}}+11471.43 \mathrm{P}_{\mathrm{f}}^{2}$

\section{CONCLUSIONS}

(1) The temperature is the main external factor affecting the splitting load, and the splitting failure load decreases with the increase of the temperature. The relationship between splitting failure load of $\mathrm{PF}$ and $\mathrm{BF}$ asphalt concrete and temperature can be expressed by Formulas (1)-(2), Formula (3) and Formula (4), respectively.

(2) The tensile strain $\varepsilon_{T}$ increases with the increase of temperature. The fiber can prevent the splitting deformation. The vertical displacement and the lateral displacement of the asphalt concrete will decrease with the increase of the fiber mixing amount when the proper amount of fiber is added.

(3) The failure stiffness modulus of asphalt concrete decreases with the increase of temperature, and the relationship between the failure stiffness modulus of ordinary asphalt concrete, $\mathrm{PF}$ and $\mathrm{BF}$ asphalt concrete and temperature is expressed by Formulas (5), (6) and (7), respectively.

(4) The effect of fiber on the splitting performance of asphalt concrete is mainly related to the distribution form, quantity and length of fibers on the fracture surface, and the optimum fiber length is about $6 \mathrm{~mm}$

(5) The relationship between the splitting failure load and the fiber mixing amount is related to the temperature. When the temperature is lower than $15^{\circ} \mathrm{C}$, the effect law of the fiber mixing amount on the splitting failure load is not obvious. At $15^{\circ} \mathrm{C}$, the linear relationship between the splitting failure load of PF and BF asphalt concrete can be expressed by Formula (8) and Formula (9), respectively.

(6) When the temperature is lower than $15^{\circ} \mathrm{C}$, the change trend of splitting tensile strength, tensile strain and failure stiffness modulus is not obvious with the increase of fiber mixing amount. At $15^{\circ} \mathrm{C}$, the linear relationship of splitting tensile strength, tensile strain and failure stiffness modulus of $\mathrm{PF}$ and $\mathrm{BF}$ asphalt concrete increase with the increase of fiber mixing amount, which can be represented by formulas (10)(15). 


\section{ACKNOWLEDGMENTS}

The authors gratefully acknowledge the financial support of the project from the Colleges and Universities Key Scientific Research Projects of Henan Province (Grant No. 17B580003) and Horizontal Research Project of Xuchang University (Grant No. 2017HX029 and 2019HX005).

\section{REFERENCES}

[1] Ji XL, Yang M, Zhou B, Fan LP. (2018). Influence factors analysis of the discrete element numerical simulation of the splitting test for asphalt mixtures at low temperature. Low Temperature Architecture Technology 9(40): 18-23. http://doi.org/10.13905/j.cnki.dwjz.2018.09.005

[2] Peng Y, Sun LJ, Shi YJ. (2007). Factors affecting splitting strength of asphalt mixture. Journal of Jilin University (Engineering and Technology Edition) 11(6): 1304-1307. http://doi.org/10.3969/j.issn.10068872.2008.06.064

[3] Peng Y, Gao H, Wan L, Liu YG. (2018). Numerical simulation of influence factors of splitting strength of asphalt mixtures. Journal of Jilin University (Engineering and Technology Edition) https://doi.org/10.13229/j.cnki.jdxbgxb20180356
[4] Wu JR, Qi DJ. (2017). Influence of polyester fiber contents and reeeze-thaw cycles on water stability of asphalt mixture. Bulletin of the Chinese Ceramic Society 4(36):

$1412-1416$. http://doi.org/10.16552/j.cnki.issn10011625.2017.04.053

[5] Ye QS, Wu SP, Li N. (2009). Investigation of the dynamic and fatigue properties of fiber-modified asphalt mixtures. International Journal of Fatigue 31(10): 15981602. http://doi.org/10.1016/j.ijfatigue.2009.04.008

[6] Lee SJ, Rust JP, Hamouda H, Kim YR, Borden RH. (2005). Fatigue cracking resistance of fiber-reinforced asphalt concrete. Textile Research Journal 2(75): 123128. http://doi.org/10.1177/004051750507500206

[7] JTJ052-2011 Standard test methods of bitumen and bituminous mixtures for highway engineering.

[8] Jiang MY, Zhang B. (2016). Evolution rules of gussasphalt concrete splitting tensile strength under the action of freeze thaw corrosion. Bulletin of the Chinese $\begin{array}{llll}\text { Ceramic } & \text { Society } & \text { 743-747. }\end{array}$ http://doi.org/10.16552/j.cnki.issn10011625.2016.03.014

[9] Cheng ZQ, Kong FS. (2016). Effect of aggregate surface energy parameters on splitting strength of asphalt mixture. Journal of Building Materials 4(19): 779-783. http://doi.org/10.3969/j.issn.1007-9629.2016.04.030 